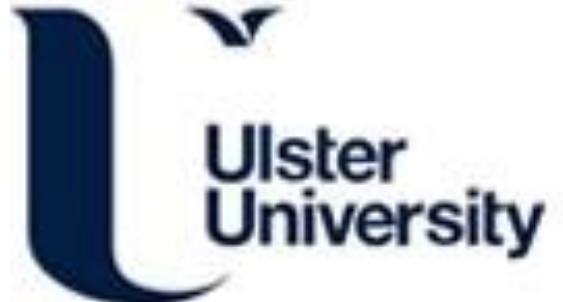

\section{Directed Functional Connectivity in Fronto-Centroparietal Circuit Correlates with Motor Adaptation in Gait Training}

Youssofzadeh, V., Zanotto, D., Wong-Lin, K., Agrawal, S., Prasad, G., \& Agrawal, S. K. (2016). Directed

Functional Connectivity in Fronto-Centroparietal Circuit Correlates with Motor Adaptation in Gait Training. IEEE Transactions on Neural Systems and Rehabilitation Engineering, 24(11), 1265-1275.

https://doi.org/10.1109/TNSRE.2016.2551642

Link to publication record in Ulster University Research Portal

Published in:

IEEE Transactions on Neural Systems and Rehabilitation Engineering

Publication Status:

Published (in print/issue): 30/11/2016

DOI:

10.1109/TNSRE.2016.2551642

Document Version

Author Accepted version

\section{General rights}

Copyright for the publications made accessible via Ulster University's Research Portal is retained by the author(s) and / or other copyright owners and it is a condition of accessing these publications that users recognise and abide by the legal requirements associated with these rights.

\section{Take down policy}

The Research Portal is Ulster University's institutional repository that provides access to Ulster's research outputs. Every effort has been made to ensure that content in the Research Portal does not infringe any person's rights, or applicable UK laws. If you discover content in the Research Portal that you believe breaches copyright or violates any law, please contact pure-support@ulster.ac.uk. 


\title{
Directed Functional Connectivity in Fronto-Centroparietal Circuit Correlates with Motor Adaptation in Gait Training
}

\author{
Vahab Youssofzadeh, Damiano Zanotto, Member, IEEE, KongFatt Wong-Lin, Member, IEEE, \\ Sunil K. Agrawal, Senior Member, IEEE, and Girijesh Prasad, Senior Member, IEEE
}

\begin{abstract}
Lower-extremity robotic exoskeletons are used in gait rehabilitation to achieve functional motor recovery. To date, little is known about how gait training and post-training are characterized in brain signals and their causal connectivity. In this work, we used time-domain partial Granger causality (PGC) analysis to elucidate the directed functional connectivity of electroencephalogram (EEG) signals of healthy adults in robotassisted gait training (RAGT). Our results confirm the presence of EEG rhythms and corticomuscular relationships during standing and walking using spectral and coherence analyses. The PGC analysis revealed enhanced connectivity close to sensorimotor areas $\left(\mathrm{C}_{3}\right.$ and $\left.\mathrm{CP}_{4}\right)$ during standing, whereas additional connectivities involve the centroparietal $\left(\mathbf{C P}_{\mathbf{z}}\right)$ and frontal $\left(\mathbf{F}_{\mathbf{z}}\right)$ areas during walking with respect to standing. In addition, significant fronto-centroparietal causal effects were found during both training and post-training. Strong correlations were also found between kinematic errors and fronto-centroparietal connectivity during training and post-training. This study suggests frontocentroparietal connectivity as a potential neuromarker for motor learning and adaptation in RAGT.
\end{abstract}

Index Terms-Active Leg Exoskeleton (ALEX II), connectivity analysis, electroencephalography, partial Granger causality, robot-assisted gait training.

\section{INTRODUCTION}

A $\mathrm{N}$ important aim of combined robot-assisted gait training and electroencephalography (EEG)-based brain-machine interface systems is to improve or regain motor function in neurotrauma or stroke patients, with the help of active gait exercises [1]. EEG has a crucial advantage of directly measuring the neural activities with a sufficient temporal resolution on the time scale of natural motor behavior [2]. Importantly, its portability allows it to be used in gait training for better evaluation of the underlying dynamics of the signals, both within (intra-stride) and across (inter-stride) gait cycles.

Several robot-assisted gait training studies have demonstrated the role of the cerebral cortex in motor behavior during steady-speed locomotion [3]-[12]. For instance, a task-related suppression (event-related desynchronization, or ERD) of $\alpha / \beta$ bands has been observed during active walking compared to upright standing/passive walking [6], [8], [9] or during

V. Youssofzadeh, G. Prasad and K. Wong-Lin are with Intelligent Systems Research Centre (ISRC), Faculty of Computing and Engineering, Ulster University, Magee Campus, Northland Road, BT48 7JL, Northern Ireland

D. Zanotto and S.K. Agrawal are with Robotics and Rehabilitation (ROAR) Lab, Columbia University, New York, NY, 10027 USA.

Corresponding author: V.Y (v.youssofzadeh-v@ulster.ac.uk) and D.Z (damiano.zanotto@columbia.edu)

Manuscript received June 18, 2015; revised Feb 11, 2016. stepping movements compared to resting [13]. This ERD effect can be changed due to gait cycle phases [6] or can be sustained during active walking [8], [12]. In addition, an increase of low $\theta(\sim 4 \mathrm{~Hz})$ band oscillations has been reported during balance control [14]. Modulations of high $\gamma(70-90 \mathrm{~Hz})$ and low $\gamma$ (24-40 Hz) rhythms in relation to gait cycle have also been reported [8]. Further pieces of evidence have been provided by multimodal data analyses. A significant coherence peak between EEG and EMG signals has been observed at the vertex electrode $\left(\mathrm{C}_{\mathrm{z}}\right)$ within the frequency band of $25-35 \mathrm{~Hz}$ during walking [15] and within the frequency range of 15-30 $\mathrm{Hz}$ during feet tonic contraction [10], [16]. However, more indepth investigations are still needed to better characterize the relationship between EEG and EMG during gait. In particular, analysis of neural connectivity dynamical changes may shed new light on this relationship.

Two recent RAGT studies have characterized neural connectivity changes to understand the underlying mechanisms of motor control, execution and recovery [4], [11]. Notably, in the first work conditional Granger causality analysis was applied to EEG signals of healthy subjects during standing and treadmill walking [4]. The independent component analysis (ICA) and inverse source modelling revealed localized activities adjacent to the anterior cingulate, posterior parietal, prefrontal and sensorimotor areas. The authors hypothesized that standing is predominantly controlled by supraspinal mechanisms whereas walking depends on spinal neural networks. The analysis suggests connections involving sensorimotor channels were stronger during standing than during walking, regardless of cognitive tasks. However, the results did not completely support the hypothesis. In the second work, structural equation modelling was conducted for resting-state fMRI data where diminished connectivity strength was found in both frontoparietal and primary motor networks for stroke survivors compared to healthy subjects [11]. Together, these two recent works have brought to light the problem regarding how gait training can be characterized in terms of changes in brain signals and their functional connectivity during human locomotion. However, it is known that conditional Granger causality and structural equation modelling do not take into account indirect (neural) connectivity and external stimulus factors [17]. Moreover, fMRI is known to have a poor temporal resolution as compared to EEG or MEG data. Hence, a more advanced connectivity measure of EEG data during human locomotion is needed for better reliability and accuracy. 
In the present work, in line with our previous work [18], we apply, on healthy participants, directed functional connectivity techniques to elucidate the interactions among brain signals in gait training with a lower-extremity exoskeleton. In particular, we use partial Granger causality (PGC) that effectively mitigates confounding influences, especially those caused by hidden endogenous (e.g. recurrent connectivity) and exogenous inputs (e.g. external stimulus influences) [19]. These unwanted influences are detected and partly factored out, similar to the partial correlation that removes the influence of known unwanted variables via a correlation measure. However, PGC can also mitigate the influence of unknown variables indirectly, i.e. through their influence on the prediction error. Importantly, PGC has been applied to neural activity signals (local field potentials) from animal [19] and event-related potentials from human [20], but not to the more challenging and noisy EEG data during human locomotion.

\section{MATERIAL AND METHODS}

\section{A. Experimental setup}

Six healthy male adults (age $26.5 \pm 6.5$ years, weight $77.8 \pm 9.7 \mathrm{~kg}$, height $1.79 \pm 0.04 \mathrm{~m}$ ) with no history of major lower limb injury and no known neurological or locomotor deficit were trained in the ALEX II system (Active Leg EXoskeleton [21], [22]) after providing informed consent. The study protocol was approved by the local Institutional Review Board, and each experiment involved a single visit to our laboratory. Leg dominance was determined by asking participants which leg they would use to kick a ball. The robotic leg was then attached to the subject's dominant leg (i.e., the right leg for all subjects), and the treadmill speed was set to the subject's comfortable walking speed $(0.87 \pm 0.15$ $\mathrm{m} / \mathrm{s}$ ) as shown in Fig. 1A.

\section{B. Protocol}

The training paradigm consisted of ten walking bouts (Fig. 1B), each preceded by a standing condition: (1) a $10 \mathrm{~min}$ bout of free treadmill walking without the robot; (2) a 5-min baseline test where the robot was controlled in transparent mode (i.e., nil interaction with the user); (3-6) four 10-min training bouts, during which the subjects were asked to match an altered footpath (the target template) derived from their baseline footpath; (7-9) three 5-min bouts of post-training tests, where the robot was controlled in transparent mode and the subjects were asked to walk normally; (10) a 5-min bout of free treadmill walking. Breaks (2-4 min) were included in between subsequent bouts.

During each training bout, subjects received haptic guidance (frequency $100 \%$ ) and a visual guidance (activated in alternating minutes, frequency $50 \%)^{1}$ from the ALEX II. The haptic

${ }^{1}$ Extrinsic visual feedback typically promotes strong dependency, especially if it is prescriptive, as in RAGT and if the task is relatively simple, as is the case of gait training. Because dependency on extrinsic feedback is detrimental for motor learning (Guidance Hypothesis, [23]), previous research has developed techniques for mitigating dependency. Reduced frequency feedback is one of these techniques [24]. The $50 \%$ value was chosen based on past studies with ALEX [25]. Haptic feedback is less prone to dependency, because it hinders processing of sensory afferences to a lesser extent than vision. For this reason, haptic feedback was applied with $100 \%$ frequency. guidance consisted of assistive forces exerted by the robot to help the user's right foot follow the target footpath. The visual guidance consisted of a computer screen located in front of the user, showing a graphical representation of the target footpath along with the current foot position.

The gait cycle was defined as the time interval between successive heel-strikes of the right leg, as measured by footswitches mounted on instrumented insoles. The baseline footpath of each subject was derived from time-normalized kinematic data, averaged over the last $30 \mathrm{sec}$ of the baseline session. The target footpath was computed by scaling down by $20 \%$ the baseline hip and knee joints trajectories, as described in [25]. This method produces a shorter and shallower target movement.

EEG data were collected at $512 \mathrm{~Hz}$ using a g.tec's g.USBamp with 16 active scalp electrodes, in accordance with the 10-20 international standard. The reference electrode was linked to an earlobe and the signal quality of all channels was continuously monitored during recording through visual inspection. It is to be noted that active electrodes do not need regular impedance check as they have an embedded amplifier chip and can record good quality EEG signals even with very high impedance (say, $500 \mathrm{k} \Omega$ ). Prior to the onset of each bout, baseline EEG was recorded for one minute as the subject stood stationary on the treadmill. We treated this part of the data as a benchmark for stability check. The causal influences obtained from these data (during upright standing) were also used to compare with those during treadmill walking.

EMG signals were recorded from six muscles of the right leg: soleus (SL), gastrocnemius medialis, tibialis anterior, vastus lateralis, rectus femoris and biceps femoris. $\mathrm{Ag} / \mathrm{AgCl}$ disposable surface electrodes with an inter-electrode distance of $20 \mathrm{~mm}$ were used. A wireless unit (Noraxon Inc., Scottsdale, Arizona) connected to the robot controller board collected EMG data at $1 \mathrm{kHz}$. Raw EMG signals were high-pass filtered with a first-order analog filter (cutoff frequency $10 \mathrm{~Hz}$ ) prior to digital conversion.

\section{Kinematic error}

To quantify each participant's performance before and after training, we computed the kinematic error using the position sensors mounted on the robotic leg. We computed the error stride-by-stride, as the deviation area between the target footpath and the movement actually performed by the subject's ankle (i.e., the current footpath). To enable inter-subject comparisons, this value was divided by the area between the target and baseline templates: This yielded the normalized error area (NEA) [25]. A perfect matching of the target trajectory resulted in $\mathrm{NEA}=0$, a footpath close to the baseline footpath resulted in $\mathrm{NEA} \approx 1$ and further deviation from baseline resulted in NEA $>1$. For each participant, we averaged the stridespecific NEA values to give a representative value per each walking bout.

\section{EEG and EMG data analysis}

The EEG signals were re-referenced to common average, and band-pass filtered in the range of $0.5-40 \mathrm{~Hz}$ to purge 
A

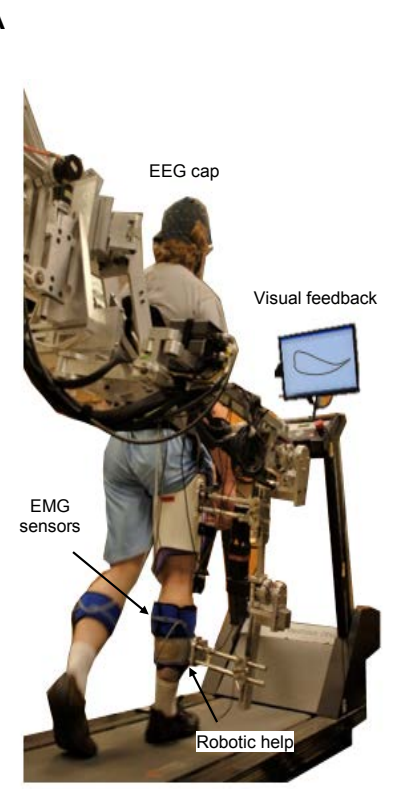

B

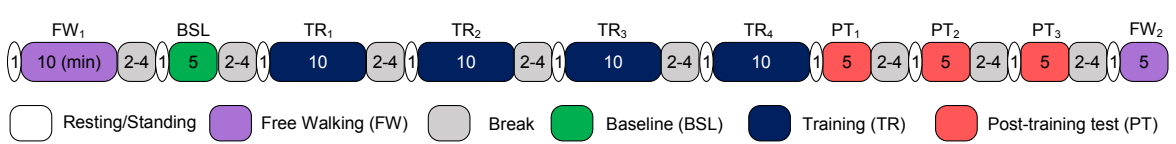

C

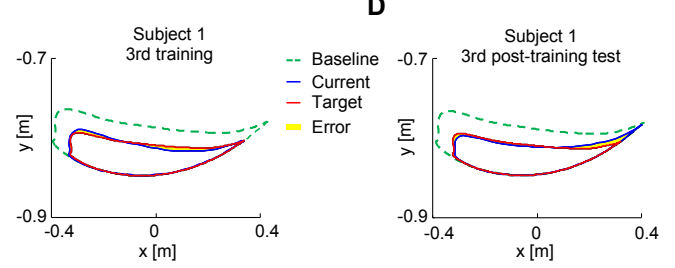

E
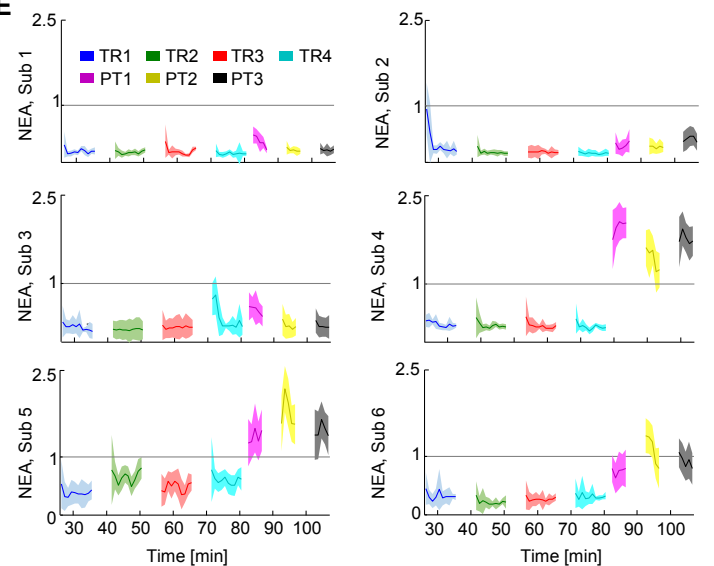

Fig. 1. Gait training and behavioral data. (A) A participant walking on a treadmill with ALEX II attached to his right leg. The computer screen in front of the participant was used to provide visual feedback of both the current footpath and the prescribed footpath. (B) Experimental protocol of gait training. The total time was almost 112 minutes. (C-D) Normalized error area (NEA) obtained from subject 1 during third training (TR (T) $_{3}$ and third post-training test $\left(\mathrm{PT}_{3}\right)$. (E) Minute-by-minute NEA profiles for each of the 6 subjects during training and post-training test trials. NEA values below unity provide kinematic evidence for motor adaptation.

unwanted ultra-low (close to DC) and high frequency noises. The Infomax ICA [26] used to remove artifacts due to eye movements, eye blinks and muscle activities. An average of two independent components whose scalp maps were significantly high were eliminated, and the remaining components were projected back onto the scalp channels and considered as artifact-corrected EEG data. We selected 10 out of 16 EEG electrodes, covering the most important brain areas involved in locomotion: prefrontal $\left(\mathrm{F}_{\mathrm{z}}\right)$, frontocentral $\left(\mathrm{FC}_{3}, \mathrm{FC}_{\mathrm{z}}, \mathrm{FC}_{4}\right)$, motor $\left(\mathrm{C}_{3}, \mathrm{C}_{\mathrm{z}}, \mathrm{C}_{4}\right)$ and centroparietal $\left(\mathrm{CP}_{3}, \mathrm{CP}_{\mathrm{z}}, \mathrm{CP}_{4}\right)$ [27]. The EMG signals were also filtered in the range $1-40 \mathrm{~Hz}$. We segmented both EMG and EEG data based on gait cycles ( $1.2 \mathrm{sec}$ ). The segments that exceeded 90 percent of the signal power of each EEG channel $(100 \pm 15 \mu \mathrm{v})$ as well as those with kurtosis greater than 3 standard deviations from the mean of each EEG channel were rejected ('peaky' distribution) [14]. Overall, an average of $18 \%$ of segments across participants was discarded.

We conducted a power spectrum density (PSD) analysis by means of fast Fourier transform on both EEG and EMG segments in standing and walking conditions and for ten tasks separately. At each channel location, the average of PSDs over all segments was computed. A pairwise coherence analysis was performed to find the synchrony between 10 EEG channels and 6 EMG channels. To reduce the spectral leakage, we computed the coherency for each segment using a Hanning window with the length of 128 and 50 percent overlap. We made no inference about the coherency between EEG and EMG signals in low frequency bands, given that the filter embedded in the recording system had cancelled out the low frequencies (below $10 \mathrm{~Hz}$ ). Compared to other EMG channels, the SL showed the highest coherency peak and was therefore analyzed in more detail (EMG-SL). Finally, we performed a Wilcoxon signed rank test $(p<0.05$, FDR corrected for multiple comparisons) on PSD and coherency values across gait cycles (segments) to look for significant differences between standing and walking conditions in four frequency bands $(\delta, \theta, \alpha$ and $\gamma)$.

To extract the causal effects, we divided the artifactcorrected EEG data into intervals lasting approximately $5 \mathrm{sec}$ (almost 4 gait cycles), with 2 sec overlapping windows. The windowing strategy can effectively reduce the probability of spurious causal effects due to nonstationarity in EEG signals [28]. Longer segments (e.g., $\mathrm{L}=10 \mathrm{sec}$ ) led to better model fitting, but they were frequently nonstationary. The 5-sec segments provided both local stationarity and rather satisfactory model fitting. The segmentation yielded about 290 segments during the first free walking and each of the four training bouts, and 120 segments during the baseline, each of the three post-training, and the second free walking bouts. To partly overcome the nonstationarity and inter-segment variations, the ensemble average was subtracted from segments and the 
segments were divided by the ensemble standard deviation [28]. We used the entropy-based Levinson-Wiggins-Robinson algorithm [29] to estimate the multivariate autoregressive (MVAR) coefficients from each EEG segment, then computed the optimal model order $p$ (i.e., the number of time-lags) of a MVAR model using both Akaikes (1973) information criterion (AIC) and Schwarz's (1978) Bayesian information criterion (BIC). We determined the optimal model order of the MVAR process as the one that minimized the AIC and BIC in the range of 1-20, corresponding to 9-170 ms. We used the PGC method to extract the influences among the brain regions at the scalp level. Fig. 2 shows the summarized vector autoregressive representation of PGC of two assumed independent sources $X_{t}$ and $Y_{t}$ that are influenced by latent variables $\left(L_{1}\right.$ and $\left.L_{2}\right)$, exogenous inputs $\left(E_{1}\right.$ and $\left.E_{2}\right)$, and the modulatory factor (driven by series $Z_{t}$ ). Under the PGC assumption, the corresponding residual error of two confounding factors $\varepsilon_{t}(E$ : exogenous) and $B_{L} \varepsilon_{L}$ ( $L$ : latent) along with residual error $\varepsilon_{t}$ can be incorporated into a MVAR representation, where $B_{L}$ is a polynomial matrix of appropriate lag operator $L$ related to latent input and depends on its history. The causal influence of $F_{Y \rightarrow X \mid Z}$ is computed as the log-ratio of the variance of residual errors in the restricted model to that in the full model, considering the covariance term to control the indirect interactions.

To confirm the validity of the regression model, Ding's consistency [28] and Durbin-Watson (whiteness) [30] tests were employed. The consistency test indicates the correlation between estimated and evaluated data, whereas the whiteness test shows how well the variance in the data has been accounted for by the model. To obtain the confidence intervals of GC effects, we performed a bootstrap resampling test [31] with 1000 samples and Bonferroni correction at a significance level $\alpha=0.05$. We computed the average of estimated source (outgoing) and sink (incoming) causal influences for each electrode location i.e. GC power, normalized them by standard deviation due to multiple subjects i.e., normalized GC power, and projected them on a topological map overlaid by significant GCs. Note that the (normalized) GC power represent the scalp activity patterns (average of influx and outflux at a particular channel area) whereas GC values indicate the propagation of signal flow from one channel to another (see black arrows in Figs. 4 and 6). Similar to PSD and coherence analyses, we performed the same FDR corrected Wilcoxon signed rank test on GC values to look for significant differences between standing and walking conditions.

EEG data pre-processing and data visualization (scalp maps) were performed in MATLAB using EEGLab 9.0.4b (sccn.ucsd.edu/eeglab) and the causal effects were extracted using multivariate granger causality toolbox 2.9 (sussex.ac.uk/sackler/mvgc). Kinematic error was analyzed using custom MATLAB scripts.

\section{RESULTS}

\section{A. Individual differences in motor adaptation}

Figs.1C-D show the kinematic error corresponding to the third training and third post-training bouts from subject 1, who showed the best retention of the target movement. We quantified the deviations from the target footpath by means of the normalized error area (NEA). Fig.1E exhibits the minuteby-minute NEA across the training and post-training bouts, for each participant. We considered the set of strides that occurred in each minute, and computed mean (solid lines) and standard deviation (shaded areas) of the NEA values corresponding to those strides. NEA values below the unitary value (i.e., the baseline NEA) indicate motor adaptation. During training, assistive forces exerted by the robot and visual feedback helped subjects reduce the deviation from the target footpath. During post-training, when the robot provided no assistance or feedback, the footpaths of subjects 1-3 remained relatively close to the target, indicating motor adaptation. This adaptation, however, was not clear in the other three subjects (4-6). In Fig. 5, we specifically investigate the correlation between kinematic error and the connectivity strength of the fronto-centroparietal scalp network. The subjects' behavioral differences are further discussed in Section IV.

\section{B. Enhanced $30 \mathrm{~Hz}$ oscillations during walking compared to standing}

The group average PSD across subjects disclosed significant changes mainly at central brain site (e.g. $\mathrm{C}_{\mathrm{z}}$ as shown in Fig. 3 ) in three frequency bands; $\alpha$ band $(8-12 \mathrm{~Hz}), \theta$ band $(4 \mathrm{~Hz})$ and $\gamma$ band $(30 \mathrm{~Hz}$ ) during walking versus standing (Fig. 3A, black vs. gray lines). However, the PSDs of EMG-SL signals revealed a significant increase in the $30 \mathrm{~Hz}$ oscillations only, especially in $\mathrm{TR}_{3}$ and $\mathrm{PT}_{3}$ (Fig. 3A, dark blue vs. light blue lines). In addition, the EEG-EMG coherence analysis yielded significant peak differences between walking and standing at the frequency range close to $30 \mathrm{~Hz}$ (Fig. 3B, red vs. orange lines). The PSD and coherency analyses for each participant (shown in Table I) were consistent with the group results in Fig. 3, indicating significant changes in delta, $\theta, \alpha$, and $\gamma$ bands during $\mathrm{TR}_{3}$ and $\mathrm{PT}_{3}$. In the coherency analysis, only the frequency responses close to $30 \mathrm{~Hz}$ showed significant changes among conditions, as reported in the Table I and shown in Fig. 3.

\section{Fronto-Centroparietal GC is highly correlated with kine- matic error}

PGC analysis was conducted on EEG segments from the 6 healthy participants. The average order of the MVAR model was $17.2 \pm 1.9$, the average of white segments was $84.5 \pm 6.4 \%$, and the average consistency test was $80.3 \pm 8.4 \%$. The PGC analysis of individuals during walking (Fig. 4) consistently revealed appreciable causal influences in four channels: the left and right sensorimotor $\left(\mathrm{C}_{3}\right.$ and $\left.\mathrm{C}_{4}\right)$, the right centroparietal $\left(\mathrm{CP}_{4}\right)$, and the frontal $\left(\mathrm{F}_{\mathrm{z}}\right)$ channels. During free walking and baseline bouts, causal effects were found at $\mathrm{C}_{3}$ and $\mathrm{CP}_{4}$ channels, consistently across participants. However, during training bouts (from $\mathrm{PT}_{1}$ to $\mathrm{TR}_{4}$ ), an overall increase of causal effects in non-sensorimotor channels was also found, particularly in the $\mathrm{F}_{\mathrm{z}}$ channel. This increase was more evident in centroparietal channels (e.g. $\mathrm{CP}_{4}$ ) during post-training test bouts (from $\mathrm{PT}_{1}$ to $\mathrm{PT}_{3}$ ). Consistent with group results, the 


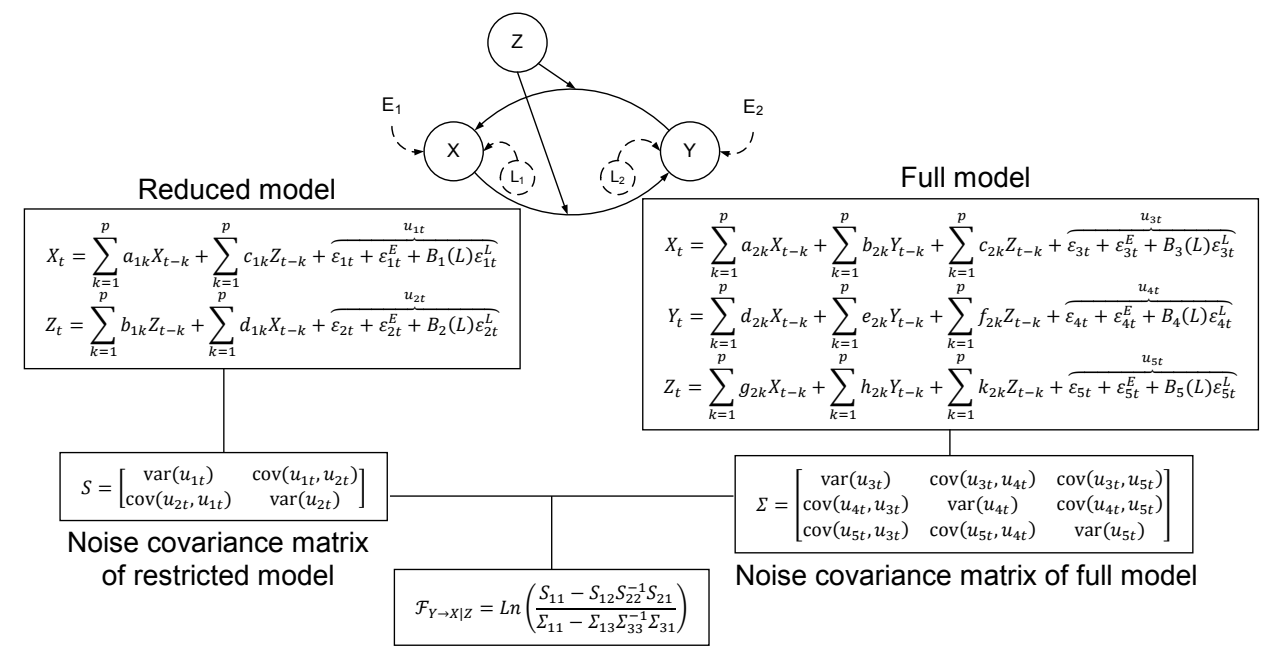

Fig. 2. The vector autoregressive representation of PGC analysis. PGC measure takes into account all (direct, indirect and unknown) effects (partial comparison). The effect of another source, exogenous input and latent variables are symbolised by $Z, E$, and $L$, respectively.

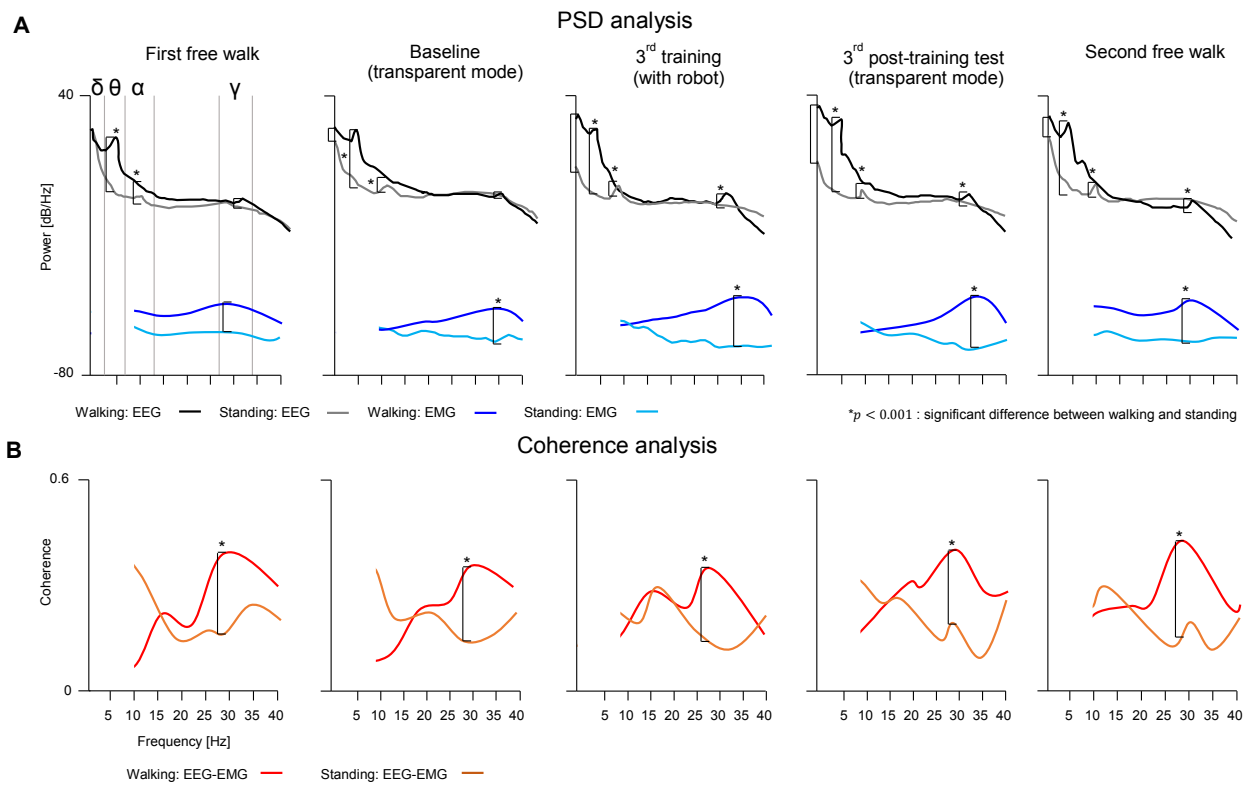

Fig. 3. PSD and coherence analyses of EEG data at $\mathrm{C}_{\mathrm{z}}$ channel and EMG data from Soleus muscle during locomotion. (A) Group PSD analysis of EEG and EMG-SL data obtained from five different tasks, including first free walking (robot not attached), baseline (transparent mode, i.e., the robotic leg was attached, but exerted nil forces on the subject's leg), training (with assistive forces and visual feedback), post-training test (transparent mode) and second free walking (robot not attached). Each bout included upright standing (1 minute recording) followed by walking (5 or 10 minutes). The PSDs of EEG signals revealed an increased $\alpha$-band $(8-12 \mathrm{~Hz})$ and and $\theta$-band $(4-7 \mathrm{~Hz})$ power in standing and walking bouts and increased low $\gamma$-band $(25-35 \mathrm{~Hz})$ power in walking only (black vs. gray). The PSDs of EMG-SL signals revealed a significant $(p<0.05$ FDR corrected signed-rank sum test) increase of power in the higher frequencies $(25-35 \mathrm{~Hz}$ ) during walking only (dark blue vs. light blue) (B) EEG-EMG coherence analysis identified a maximal peak occurring at $\sim 30 \mathrm{~Hz}$ during walking condition.

PGC analysis for single individuals given in Table II revealed significant increase of $\mathrm{CP}_{\mathrm{z}} \rightarrow \mathrm{F}_{\mathrm{z}}$ during $\mathrm{TR}_{3}$ and $\mathrm{F}_{\mathrm{z}} \rightarrow \mathrm{CP}_{\mathrm{z}}$ during $\mathrm{PT}_{3}$.

Next, we investigated the possible interactions between behavioral performance and GC estimates. We chose the fronto-centroparietal causal effect $\left(\mathrm{F}_{\mathrm{z}} \leftrightarrow \mathrm{CP}_{\mathrm{z}}\right)$ due to its major alterations observed during $\mathrm{TR}_{3}$ and $\mathrm{PT}_{3}$, see Fig. 4. We computed the Pearson's (linear) correlation coefficient of the NEAs with three possible combinations of causal effects: unidirectional centroparietal-to-frontal $\left(\mathrm{CP}_{\mathrm{z}} \rightarrow \mathrm{F}_{\mathrm{z}}\right)$, unidirectional frontal-to-centroparietal $\left(\mathrm{F}_{\mathrm{z}} \rightarrow \mathrm{CP}_{\mathrm{z}}\right)$ and the average of these two $\left(\mathrm{F}_{\mathrm{z}} \leftrightarrow \mathrm{CP}_{\mathrm{z}}\right)$. First, the correlation between NEAs and $\mathrm{CP}_{\mathrm{z}} \rightarrow \mathrm{F}_{\mathrm{z}}$ revealed relatively high values $r_{P}=-0.76(p=$ $0.07)$ and $-0.79(p=0.059)$ for third training bouts $\left(\mathrm{TR}_{3}\right)$ and post-training test $\left(\mathrm{PT}_{3}\right)$, respectively (Fig. 5A). This high correlation indicated that the subjects with better performances (i.e., the first three subjects) led to higher $\mathrm{CP}_{\mathrm{z}} \rightarrow \mathrm{F}_{\mathrm{z}}$ causal effect with stronger influences during the post-training test than training. The second correlation between the NEAs and $\mathrm{F}_{\mathrm{z}} \rightarrow \mathrm{CP}_{\mathrm{z}}$ causal effect yielded the weakest correlation for 
TABLE I

SIGNIFICANT CHANGE ON THE DIFFERENCE IN PSD AND COHERENCE BETWEEN WALKING AND STANDING.

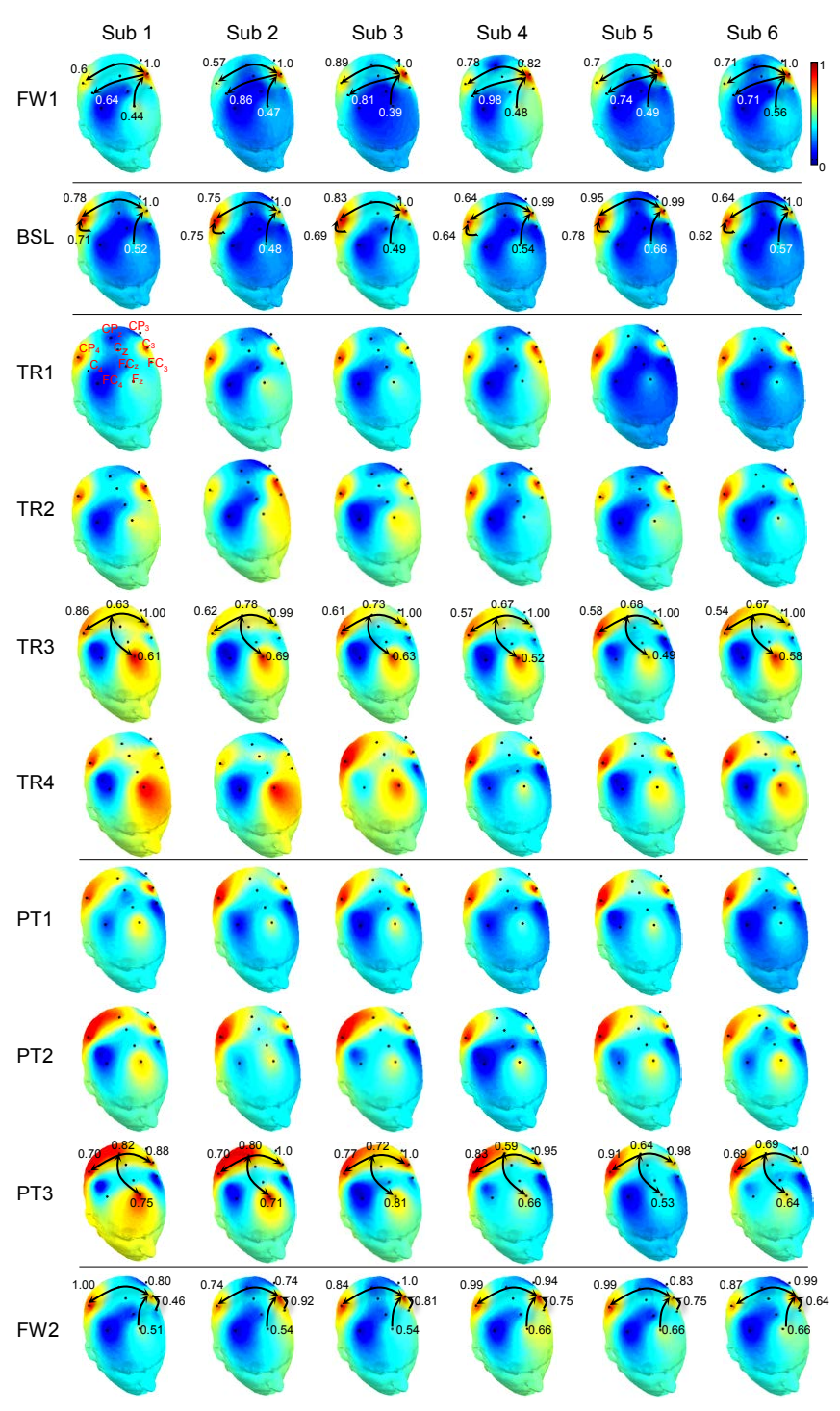

Fig. 4. Functional scalp maps obtained from PGC analysis of six healthy subjects during 10 walking bouts, consisting of first free walking (1), baseline $(2), 1^{\text {st }}-4^{\text {th }}$ training $(3-6), 1^{\text {st }}-3^{\text {rd }}$ post-training test (7-9), and second free walking (10). The GC magnitudes, i.e., the average outgoing and incoming causal effects, are projected on EEG scalp maps where significant GC directions are also overlaid. The black arrows indicate the direction of effect, whereas strength is given in the label at the end of each arrow. For example, a significant causal effect was found from $\mathrm{C}_{3}$ to $\mathrm{CP}_{4}$ during $1^{\text {st }}$ free walking with a value of 0.6 . For illustration, the significant GCs on scalp maps are overlaid only for $1^{\text {st }}$ free walking, baseline, $3^{\text {rd }}$ training, $3^{\text {rd }}$ post-training and $2^{\text {nd }}$ free walking bouts. The results indicate a consistent pattern of GCs across subjects: localized causal effects in bilateral sensorimotor areas $\left(\mathrm{C}_{3}\right.$ and $\mathrm{C}_{4}$ ) during the $1^{\text {st }}$ and $2^{\text {nd }}$ free walking and baseline bouts, an increase of connectivity couplings in frontal channel over the training and an increase of connectivity couplings in fronto-centroparietal channel over the post-training bouts. The mentioned changes were more obvious in the first three subjects, which was consistent with their performances shown in Fig. 1E.

\begin{tabular}{|c|c|c|c|c|c|c|c|}
\hline Data & $\begin{array}{l}\text { freq. } \\
\text { band } \\
(\mathrm{Hz})\end{array}$ & s1 & s2 & s3 & s4 & s5 & s6 \\
\hline PSD (EEG, TR « vs. standing) & $\begin{array}{l}\delta \\
\theta\end{array}$ & $\begin{array}{l}\mathrm{ns}^{+} \\
\mathrm{ns}^{+}\end{array}$ & $\begin{array}{c}\mathrm{ns}^{+} \\
+ \\
+\end{array}$ & $\begin{array}{l}n s^{+} \\
n s^{+}\end{array}$ & $\begin{array}{l}\mathrm{ns}^{+} \\
\mathrm{ns}^{+}\end{array}$ & $\begin{array}{l}n s^{+} \\
n s^{+}\end{array}$ & $\begin{array}{l}\mathrm{ns}^{+} \\
\mathrm{ns}^{+}\end{array}$ \\
\hline & $\begin{array}{l}\alpha \\
y\end{array}$ & $\mathrm{~ns}^{+}$ & + & $\mathrm{ns}^{+}$ & $\mathrm{ns}^{+}$ & $\begin{array}{c}\text { ns } \\
+ \\
+\end{array}$ & + \\
\hline $\begin{array}{l}\text { PSD (EMG-SL, TR, vs. standing) } \\
\text { Coh, (EFG EMG) }\end{array}$ & $\begin{array}{l}y \\
y \\
y\end{array}$ & $\begin{array}{l}\mathrm{ns}^{+} \\
\mathrm{ns}^{+}\end{array}$ & $\begin{array}{l}n s^{+} \\
n s^{+}\end{array}$ & $\begin{array}{c}10 \\
+ \\
+\end{array}$ & $\begin{array}{l}\mathrm{nn}^{+} \\
\mathrm{ns}^{+}\end{array}$ & $\begin{array}{c}\text { ns }^{+} \\
+\end{array}$ & $\begin{array}{c}\mathrm{ns}^{+} \\
+\end{array}$ \\
\hline PSD (EEG, TR 2 vss. standing) & $\begin{array}{l}r \\
\delta \\
\theta\end{array}$ & $\begin{array}{c}n=n^{+} \\
n^{+} \\
+\end{array}$ & 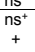 & $\begin{array}{l}\mathrm{ns}^{+} \\
\mathrm{ns}^{+}\end{array}$ & $\begin{array}{c}n n^{+} \\
+ \\
+\end{array}$ & $\begin{array}{l}\mathrm{ns}^{+} \\
\mathrm{ns}^{+}\end{array}$ & $\begin{array}{l}\mathrm{ns}^{+} \\
\mathrm{ns}^{+}\end{array}$ \\
\hline & $\begin{array}{c}a \\
y\end{array}$ & $\mathrm{~ns}^{+}$ & + & $\mathrm{ns}^{+}$ & $\mathrm{ns}^{+}$ & $\mathrm{ns}^{+}$ & \\
\hline $\begin{array}{l}\text { PSD (EMG-SL, TR2 vs. standing) } \\
\text { Coh (EEG EMG) }\end{array}$ & $\begin{array}{l}y \\
y \\
y\end{array}$ & $\begin{array}{c}a_{1} \\
+ \\
+\end{array}$ & $\begin{array}{c}\mathrm{ns}^{+} \\
+\end{array}$ & $\begin{array}{c}10 \\
+ \\
+\end{array}$ & $\begin{array}{l}\mathrm{ns}^{+} \\
\mathrm{ns}^{+}\end{array}$ & $\begin{array}{l}x^{2} \\
+ \\
\mathrm{ns}^{+}\end{array}$ & $\begin{array}{l}n^{2} \\
\text { ns }^{+} \\
\text {s }^{+}\end{array}$ \\
\hline PSD (EEG, TR 3 vss. standing) & $\begin{array}{l}r \\
\delta \\
\theta\end{array}$ & $\begin{array}{l}n s^{+} \\
n^{+}\end{array}$ & $\begin{array}{c}n^{+} \\
+ \\
+\end{array}$ & $\begin{array}{l}\mathrm{ns}^{+} \\
\text {ns }^{+}\end{array}$ & $\begin{array}{c}n^{3} s^{+} \\
+\end{array}$ & $\begin{array}{c}n n^{+} \\
+ \\
+\end{array}$ & $\begin{array}{c}\mathrm{ns}^{+} \\
+ \\
+\end{array}$ \\
\hline “ & a & 氵 & & t & ns & ns. & - \\
\hline PSD (EMG-SL, TR 3 vs. standing) & $\begin{array}{l}y \\
y\end{array}$ & + & 喿 & + & $\mathrm{ns}^{+}$ & + & ns ${ }^{+}$ \\
\hline $\begin{array}{c}\text { Cho. (EEG, EMG) } \\
\text { PSD (EE, TRA ss. standing) }\end{array}$ & $\frac{y}{\delta}$ & $\mathrm{ns}^{+}$ & $\frac{n^{+}}{n s^{+}}$ & $\frac{n^{+}}{n^{+}}$ & $\frac{n^{5}}{n s^{+}}$ & $\begin{array}{c}+ \\
\mathrm{ns}^{+} \\
n^{+}\end{array}$ & $\begin{array}{ll}\mathrm{ns}^{+} \\
\mathrm{ns}^{+} \\
n^{+}\end{array}$ \\
\hline & $\theta$ & & & & & $\mathrm{ns}^{+}$ & \\
\hline & $\begin{array}{l}\alpha \\
y\end{array}$ & $\mathrm{~ns}^{+}$ & + & $\mathrm{ns}^{+}$ & + & $\begin{array}{l}\text { ns- } \\
\text { ns. }\end{array}$ & $\mathrm{ns}^{+}$ \\
\hline $\begin{array}{l}\text { PSD (EMG-SL, TR4 vs. standing) } \\
\text { Ch. (EEG EMG) }\end{array}$ & y & $\begin{array}{c}+ \\
\text { ns }^{+}\end{array}$ & $\stackrel{+}{+}$ & $\stackrel{+}{+}$ & $\begin{array}{l}\mathrm{ns}^{+} \\
\text {nst }^{+}\end{array}$ & $\underset{\mathrm{ns}^{+}}{+}$ & $\begin{array}{c}\mathrm{ns}^{+} \\
\text {ss }^{+}\end{array}$ \\
\hline PSD (EEG, PT/ vs. standing) & $\frac{\delta}{\delta}$ & $\mathrm{ns}^{+}$ & $\begin{array}{ll}\mathrm{ns}^{+} \\
\text {nst }\end{array}$ & $\mathrm{ns}^{+}$ & $\mathrm{ns}^{+}$ & $\mathrm{nst}^{+}$ & $\mathrm{ns}^{+}$ \\
\hline (a) & ${ }_{\alpha}^{\theta}$ & & $\begin{array}{l}\mathrm{ns}^{+} \\
\text {ns. }^{-}\end{array}$ & $\begin{array}{c}\text { ns }^{+} \\
\text {ns. }\end{array}$ & & & $\stackrel{+}{+}+^{+}$ \\
\hline “ & y & $\mathrm{ns}^{+}$ & nst & + & $\mathrm{ns}^{+}$ & $\mathrm{ns}^{+}$ & $\mathrm{ns}^{+}$ \\
\hline $\begin{array}{l}\text { PSD (EMG-SL, PTivs. standing) } \\
\text { Col LEFG EMG) }\end{array}$ & $\begin{array}{c}y \\
y \\
y\end{array}$ & $\begin{array}{c}\text { ns }^{+} \\
\text {nst }\end{array}$ & + & $\begin{array}{l}\mathrm{ns}^{+} \\
\mathrm{ns}^{+}\end{array}$ & $\begin{array}{l}\mathrm{nn}^{+} \\
\mathrm{ns}^{+}\end{array}$ & $\begin{array}{l}\mathrm{ns}^{+} \\
\mathrm{ns}^{+}\end{array}$ & $\begin{array}{l}\mathrm{ns}^{+} \\
\mathrm{ns}^{+}\end{array}$ \\
\hline $\begin{array}{l}\text { Con. (EEG, EMG) } \\
\text { PSD (EEG, PT vs. standing) }\end{array}$ & $\frac{r}{\delta}$ & $\mathrm{ns}^{+}$ & $\mathrm{ns}^{+}$ & $\frac{n s^{+}}{n s^{+}}$ & $\frac{n^{5}}{n^{+}}$ & $\frac{n n^{+}}{n s^{+}}$ & $\frac{n s^{+}}{n s^{+}}$ \\
\hline “ & $\stackrel{\theta}{a}$ & & & & $\begin{array}{c}+ \\
n s\end{array}$ & $\begin{array}{c}n \mathrm{~ns}^{+} \\
\text {ns: }\end{array}$ & \\
\hline DSD & & + & & & nst & + & $\begin{array}{c}15 \\
+\end{array}$ \\
\hline PSD (EMG-SL, PT 2 vs. standing) & r & $\mathrm{ns}^{+}$ & + & ns $^{+}$ & $\mathrm{ns}^{+}$ & ns & $\mathrm{ns}^{+}$ \\
\hline $\begin{array}{c}\text { Cho. (EEG, EMG) } \\
\text { PSD (EE, PT vs. standing) }\end{array}$ & $\begin{array}{l}y \\
\delta \\
\theta\end{array}$ & $\begin{array}{l}\mathrm{ns}^{+} \\
\mathrm{ns}^{+} \\
+\end{array}$ & $\begin{array}{c}\mathrm{nS} \\
+ \\
+\end{array}$ & $\begin{array}{l}n S^{n} \\
n^{+} \\
n s^{+}\end{array}$ & $\begin{array}{ll}\mathrm{nS}^{2} \\
\mathrm{~ns}^{+} \\
+\end{array}$ & $\begin{array}{ll}\mathrm{ns}^{+} \\
\mathrm{ns}^{+}\end{array}$ & $\begin{array}{ll}\mathrm{nS}^{+} \\
\mathrm{ns}^{+} \\
\mathrm{ns}^{+}\end{array}$ \\
\hline " & 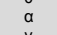 & & & & & & \\
\hline PSD (EMG-SL, PT 3 vs. standing) & $\begin{array}{l}y \\
y\end{array}$ & \pm & $\mathrm{ns}^{+}$ & $\begin{array}{c}\mathrm{ns}^{+} \\
+\end{array}$ & $\begin{array}{c}\mathrm{n}^{\mathrm{s}} \mathrm{s} \\
+\end{array}$ & $\begin{array}{lll}n_{n}^{+} \\
n^{+}\end{array}$ & ns $^{+}$ \\
\hline
\end{tabular}

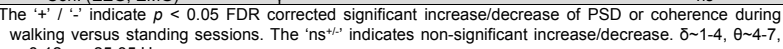
$\alpha \sim 8-12, y \sim 25-35 \mathrm{~Hz}$.

TABLE II

SigNIFICANT DIFFERENCE IN PGC BETWEEN WALKING AND STANDING DURING FOUR TRAINING AND THREE POST-TRAINING TASKS.

\begin{tabular}{|c|c|c|c|c|c|c|c|}
\hline Task & Causal effect & S1 & S2 & S3 & S4 & S5 & S6 \\
\hline $\begin{array}{l}\mathrm{TR}_{1} \text { vs. standing } \\
\mathrm{TR}_{2} \text { vs. standing }\end{array}$ & $\mathrm{CP}_{\mathrm{z}} \rightarrow \mathrm{F}_{\mathrm{z}} / \mathrm{F}_{\mathrm{z}} \rightarrow \mathrm{CP}_{\mathrm{z}}$ & $\begin{array}{l}\mathrm{ns}^{+} / \mathrm{ns}^{-} \\
\mathrm{ns}^{+} / \mathrm{ns}^{+}\end{array}$ & $\begin{array}{l}\mathrm{ns}^{+} / \mathrm{ns}^{+} \\
\mathrm{ns}^{+} / \mathrm{ns}^{-}\end{array}$ & $\begin{array}{c}\mathrm{ns}^{+} / \mathrm{ns}^{-} \\
+/ \mathrm{ns}^{+}\end{array}$ & $\begin{array}{l}\mathrm{ns}^{-} / \mathrm{ns}^{-} \\
\mathrm{ns}^{+} / \mathrm{ns}^{+}\end{array}$ & $\begin{array}{l}\mathrm{ns}^{+} / \mathrm{ns}^{+} \\
\mathrm{ns}^{+} / \mathrm{ns}^{+}\end{array}$ & $\begin{array}{l}\mathrm{ns}^{+} / \mathrm{ns}^{-} \\
\mathrm{ns}^{+} / \mathrm{ns}^{+}\end{array}$ \\
\hline $\mathrm{TR}_{3}$ vs. standing & “ & $+/+$ & $+/+$ & $+/+$ & $\mathrm{ns}^{+} /+$ & $+/ \mathrm{ns}^{+}$ & $+/ \mathrm{ns}^{+}$ \\
\hline $\mathrm{TR}_{4}$ vs. standing & . & $+/ \mathrm{ns}^{+}$ & $+/ \mathrm{ns}^{+}$ & $+/+$ & $\mathrm{ns}^{+} / \mathrm{ns}^{+}$ & $\mathrm{ns}^{+} / \mathrm{ns}^{+}$ & $+/ \mathrm{ns}^{-}$ \\
\hline $\mathrm{PT}_{1}$ vs. standing & " & $\mathrm{ns}^{+} /+$ & $\mathrm{ns}^{-} / \mathrm{ns}^{+}$ & $\mathrm{ns}^{-} / \mathrm{ns}^{+}$ & $\mathrm{ns}^{-} / \mathrm{ns}^{+}$ & $\mathrm{ns}^{-} / \mathrm{ns}^{+}$ & $\mathrm{ns}^{*} / \mathrm{ns}^{+}$ \\
\hline $\mathrm{PT}_{2}$ vs. standing & “ & $+/ \mathrm{ns}^{+}$ & $\mathrm{ns}^{+} / \mathrm{ns}^{+}$ & $\mathrm{ns}^{+} /+$ & $\mathrm{ns}^{+} / \mathrm{ns}^{+}$ & $\mathrm{ns}^{+} / \mathrm{ns}^{+}$ & $\mathrm{ns}^{+} / \mathrm{ns}$ \\
\hline $\mathrm{PT}_{3}$ vs. standing & “ & $+/+$ & $+/+$ & $+/+$ & $n s^{2} /+$ & $\mathrm{ns}^{+} /+$ & $\mathrm{ns}^{+} /+$ \\
\hline
\end{tabular}

training $r_{P}=-0.11(p=0.85)$ and rather high correlation $r_{P}=-0.65(p=0.15)$ for post-training test (Fig. 5B), suggesting $\mathrm{F}_{\mathrm{z}} \rightarrow \mathrm{CP}_{\mathrm{z}}$ influences are more associated with the post-training test than training. Finally, we found a significant correlation, $r_{P}=-0.81(p=0.047)$, between NEAs and $\mathrm{F}_{\mathrm{z}} \leftrightarrow \mathrm{CP}_{\mathrm{z}}$ for post-training test, whereas no significant correlation was found for the same correlation during training, $r_{P}=-0.57(p=0.34)$ as in Fig. 5C. The summarized results in Fig. 5D suggest that the highest (negative) correlation can be obtained by incorporating the $\mathrm{CP}_{\mathrm{z}} \rightarrow \mathrm{F}_{\mathrm{z}}$ effect for training and $\mathrm{F}_{\mathrm{z}} \leftrightarrow \mathrm{CP}_{\mathrm{z}}$ effect for post-training test. As there seemed to be some monotonic trends in the data, we also conducted further correlation analyses using the Spearman test $\left(r_{S}\right)$ and found relatively higher correlation between NEAs and causal effects (Fig. 5E). Similarly, the highest correlations for training and post-training test were obtained using $\mathrm{CP}_{\mathrm{z}} \rightarrow \mathrm{F}_{\mathrm{z}}\left(r_{S}=-0.82\right.$, $p=0.05)$ and $\mathrm{F}_{\mathrm{z}} \leftrightarrow \mathrm{CP}_{\mathrm{z}}\left(r_{S}=-0.94, p=0.01\right)$, respectively.

\section{DISCUSSION}

We have used time-domain PGC to elucidate the cross-bout information of directed causal connectivity changes through 

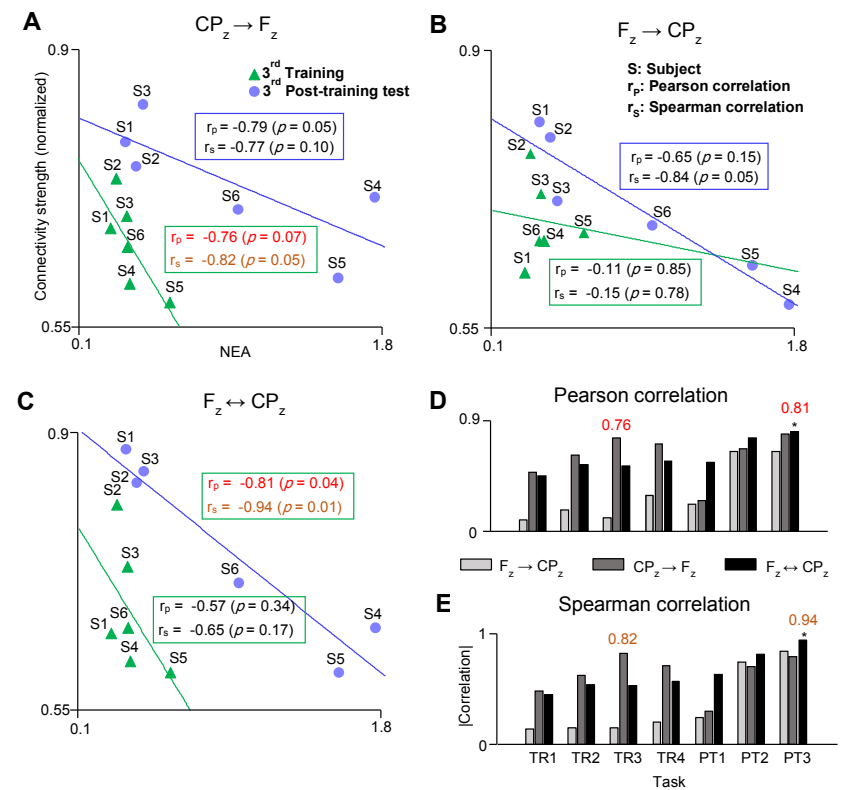

Fig. 5. Correlation between kinematic errors (or NEAs) and connectivity strength of fronto-centroparietal network during training and post-training bouts for six healthy subjects. Correlation between error and the strength of (A) centroparietal-to-frontal causal effect $\left(\mathrm{CP}_{\mathrm{z}} \rightarrow \mathrm{F}_{\mathrm{z}}\right)$, (B) frontal-tocentroparietal causal effect $\left(\mathrm{F}_{\mathrm{z}} \rightarrow \mathrm{CP}_{\mathrm{z}}\right)$, (C) average of $\mathrm{CP}_{\mathrm{Z}} \rightarrow \mathrm{F}_{\mathrm{z}}$ and $\mathrm{F}_{\mathrm{z}} \rightarrow \mathrm{CP}_{\mathrm{Z}}$ (i.e. $\mathrm{F}_{\mathrm{Z}} \leftrightarrow \mathrm{CP}_{\mathrm{Z}}$ ) causal effects during third training and third post-training bouts. (D-E) Group Pearson and Spearman correlation results accompanied with the $p$-value significance values for each bout, respectively. Star symbols show that the correlation between NEAs and GCs are statistically significant $(p<0.05)$. The green and blue lines represent the linear regression between GCs and NEAs for training and post-training test, respectively.

EEG signals in healthy participants during upright standing and treadmill walking in a robotic brace. To complement the PGC analysis and to search for potential cross talk between muscular and cortical electrical activities, we carried out PSD and coherence analyses of EEG (mainly at $\mathrm{C}_{\mathrm{z}}$ channel) and EMG-SL signals. Our analysis yielded five major findings. First, PSD analysis showed an increase of $\alpha$ rhythm during standing and $\theta$ and $\gamma$ rhythms during active walking. Second, EEG-EMG coherence analysis suggested a strong corticomuscular interplay at $30 \mathrm{~Hz}$ during walking. Third, the PGC analysis demonstrated the modulation of cortical activities during gait training bouts. It also disclosed distinguished causal effects close to the sensorimotor channels during standing and close to both sensorimotor and non-sensorimotor (particularly frontal and centroparietal) channels during walking. Fourth, the connectivity strength differences between walking and standing suggested that the frontal channel is more involved during walking than in standing. Fifth, and most importantly, we found strong correlations between kinematic errors and fronto-centroparietal connectivity strengths, especially during the post-training bouts. This finding could potentially be used to help indicate the level of motor learning and adaptation. In fact, these areas are known to be involved in sensorimotor learning, perceptual decision-making and "top-down" cognitive control [32], [33].

Fig. 1E illustrates the effect of robotic assistance on the subjects' footpath. We found low NEA values during training, and relatively higher NEA values during the post-training tests. Indeed, during training the robot applied assistive forces perpendicular to the target template and directed towards the template to help subjects match the target movement. These forces were null within a $10 \mathrm{~mm}$-wide tunnel built around the target template, whereas beyond this tunnel their magnitude increased quadratically with the distance from the target template. Such assistance was not in place during the post-training tests. In the post-training tests there was a clear difference between the first three and the last three participants. Subjects 1, 2 and 3 showed retention of the target footpath, their NEA being below unity during all the post-training bouts. Conversely, the footpaths of subjects 4, 5, 6 after training deviated from the target template even further than their baseline footpath, as suggested by NEA values being greater than unity. The post-training differences in the NEA values between well- and poorly adapted subjects were substantially high. Therefore, it is reasonable to hypothesize that subjects who focused the most on the task (i.e., subjects 1-3 who showed higher neural activity and connectivity strengths) had lower kinematic errors. Previous literatures have shown a strong correlation of functional couplings in frontal, central and parietal brain cortical areas with levels of mental fatigue [34]. Weakening in the strength of EEG-EMG coherency in $\gamma(35-50 \mathrm{~Hz}) / \beta(15-35 \mathrm{~Hz})$ frequency band due to the same effect has also been reported [35], [36]. Consistently, the within group PGC analysis in Table II yielded a significant fronto-centroparietal causal effect mainly in participants with better performances (subject 1-3). Moreover, adaptation after attentional lapses has been shown to be linked to parietooccipital $\alpha$ power and parieto-occipitalfrontal $\alpha$ synchronization [37]. The within subjects PSD and coherency analysis in Table I revealed significant changes of $\alpha$ band mainly in participants with better performances.

From PSD analysis of EEG segments, we have found power rises in the $\alpha$ band $(10 \mathrm{~Hz})$ and low $\theta$ band $(4 \mathrm{~Hz})$ power during standing and walking, respectively (Fig. 3A). The power rise in $\alpha$ band power was expected, since subjects were more in the static motor state while standing. These results are in agreement with identified ERD effect ( $\alpha$ suppression) in previous works [6], [9], [38] and increased $\theta$ oscillations during balance control [14]. Our coherence analysis suggested a high corticomuscular interplay at $30 \mathrm{~Hz}$ during walking (Fig. 3B). This can be related to a higher level of induced rhythmic cortical activity, i.e. a synchronization between an active muscle and cortical (central) channels via the corticospinal tract, during active walking compared to standing. Our analysis is also consistent with that of Petersen et al. [15], who reported a peak synchrony between EEG and EMG signals at the vertex electrode $\left(C_{z}\right)$ within the frequency band of $25-35 \mathrm{~Hz}$.

The estimated causal interactions from individual subjects during upright standing showed a largely symmetrical pattern over bilateral sensorimotor channels (Fig. 4). These influences were more widespread in the right side compared to the left side, where they were relatively more localized (Figs. 6A-B). This was also noticed in the first and second free walking and baseline walking bouts, where they exhibited pronounced causal effects in $\mathrm{C}_{3}, \mathrm{C}_{4}$ and $\mathrm{CP}_{4}$ channels, clearly due to motor activity, given the null or minimal impedance exerted 
A

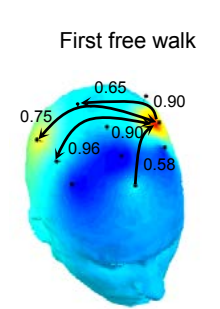

B

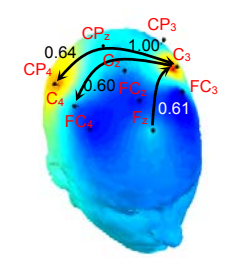

C

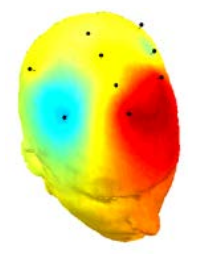

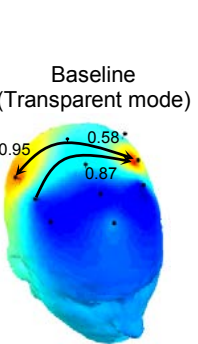

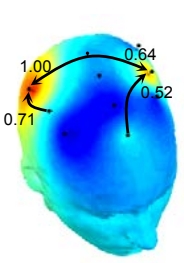

Standing (1 min)

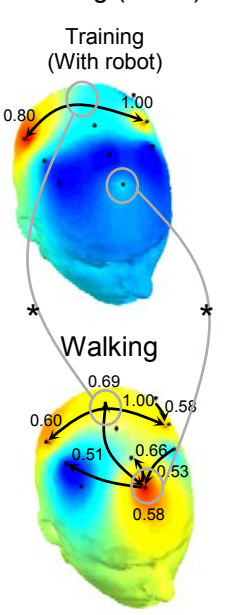

Walking - Standing

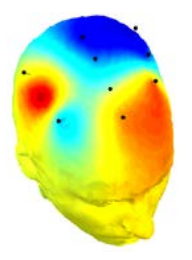

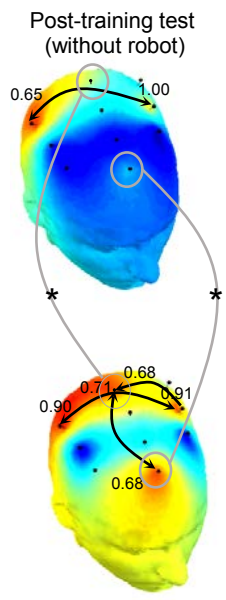

Second free walk
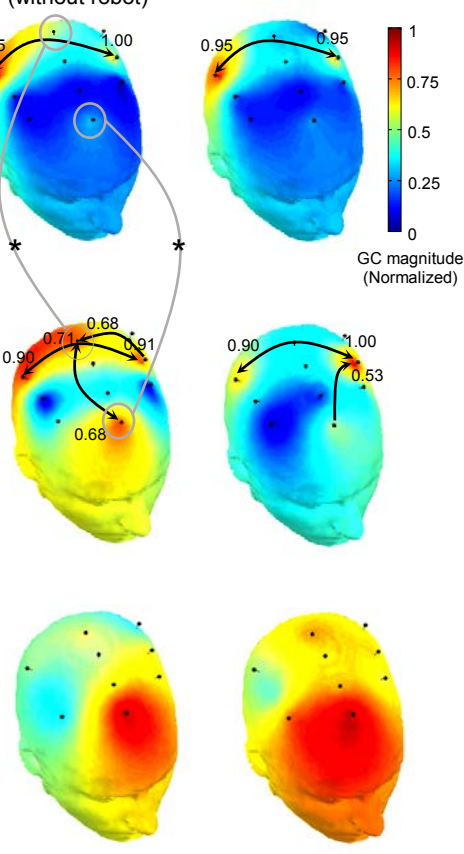

Fig. 6. Functional scalp maps obtained from group PGC analysis of six subjects during standing and walking. Group PGC analysis of (A) upright standing, (B) active walking, and (C) subtraction of standing from walking. The GC magnitudes, i.e., the average outgoing and incoming causal effects, are projected on EEG scalp maps where significant GC directions $(p<0.05$ FDR corrected) are also overlaid. The stars indicate the regions where we found significant changes in GC power between walking and standing conditions.

by the robotic leg in these bouts [39]. Analogous localized effects were observed in the second free walking, but with additional influences in the frontal area $\left(\mathrm{C}_{\mathrm{z}}\right.$ channel), possibly due to persistent motor adaptation effects. For training and post-training bouts, the estimated GCs evidenced spreading of interactions in non-sensorimotor areas (right centroparietal $\mathrm{CP}_{4}$ and frontal $\mathrm{F}_{\mathrm{z}}$ ) during active walking. This is consistent with the recent work by Bulea et al. [12], reporting enhanced activations in frontal and parietal cortical areas during active compared to passive treadmill walking. Interestingly, we found significant $\mathrm{CP}_{\mathrm{z}} \rightarrow \mathrm{F}_{\mathrm{z}}$ and $\mathrm{F}_{\mathrm{Z}} \rightarrow \mathrm{CP}_{\mathrm{z}}$ causal effects during training and post-training with respect to their (baseline) standing conditions, Figs. 6A-B. Moreover, the connectivity strength differences between walking and standing revealed a strong frontal effect (Fig. 6C). This was possibly due to the higher demand of attentional and balance control processes during active walking compared to upright standing.

As shown in Figs. 6B and 4, PGC analysis evidenced pronounced $\mathrm{GC}$ power in the $\mathrm{F}_{\mathrm{Z}}$ during training, and in the $\mathrm{CP}_{\mathrm{Z}}$ during post-training with respect to other scalp regions. The stronger $\mathrm{GC}$ power in the $\mathrm{F}_{\mathrm{z}}$ during training bouts were possibly due to the experimental protocol, which included visual and haptic feedback. This might have induced combined visuospatial processing and "top-down" attentional effects [1]. Indeed, the visual feedback provided during training required sustained attention to the mismatch between the prescribed footpath and the current foot position (frontal cortex), along with visuospatial processing to convert the abstract representation of the foot motion displayed in front of the subject to useful spatial information (parietal cortex) [40]. In contrast to training, the dominance of $\mathrm{GC}$ power in $\mathrm{CP}_{\mathrm{z}}$ during the posttraining bouts were probably caused by adaptation and balance control to account for sudden removal of the constraining robotic force [14]. Furthermore, the more intense causal effects in the left hemisphere were probably related to the robotic device being unilateral. Since the ALEX II was attached to the right leg, increased effects might have been induced in the contralateral (left) side of the brain (see Figs. 4 and 6B). Interestingly, the causal effects in the fronto-parietal network has been suggested as an indicator of the level of deficit in stroke patients during top-down processes [11]. To check for this hypothesis, we have examined the correlation between a behavioral metric, i.e., the kinematic error, and the strength of coupling between the frontal and centroparietal scalp channels (Fig. 5). Surprisingly, by testing three different combinations we found high negative correlations between the strength of $\mathrm{CP}_{\mathrm{z}} \rightarrow \mathrm{F}_{\mathrm{z}}$ causal effect during training and $\mathrm{F}_{\mathrm{z}} \leftrightarrow \mathrm{CP}_{\mathrm{z}}$ coupling strengths during post-training, suggesting that those can potentially be considered as indicators of the level of motor recovery and neurofeedback-based adaptation in stroke patients.

The connectivity strength differences between walking and standing across seven bouts have unanimously singled out the involvement of the frontal channel during walking (Fig. 6C). This may perhaps be related to the anterior cingulate cortex (ACC), which is believed to be responsible for error detection and correction, conflict monitoring and attention [41], [42]. Consistently, the strength of causal effects of the frontal chan- 
nel with respect to other scalp channels was maximal during training in our study (see Fig. 6B). Furthermore, locomotion or motor task studies involving EEG or fMRI have demonstrated the involvement of ACC in monitoring postural stability, error detection and attentional processes related to self-monitored movement [4], [5], [43].

Applying PGC to low-density EEG signals has allowed us to effectively quantify the cortical contributions to RAGT in healthy subjects. This has potential applications for real-time neurofeedback during neurorehabilitation of clinical populations with lower limb disabilities, such as stroke patients. In future work, this approach can be further validated by using a larger sample size, high-density and longer duration of recording, and more detailed analysis. In particular, the linearly mixed (correlated) noise due to volume conduction is also a challenging problem for scalp-based GC analysis. Results have shown that classical methods such as ICA decomposition [44], source localization [45] or spatial filtering [46], [47] can partially solve the issue. Recently, Vinck et al. [48] demonstrated that excluding strong instantaneous influences (zero-lag coefficients) in the MVAR model can effectively prevent false positives or spurious results. The suggested technique was tested on two relatively simple GC measures, phase slope index and reversed Granger testing. Nevertheless, in our work, additive noises were accounted for by latent and exogenous contributions. Combining this strategy with PGC could be an interesting topic for future work.

\section{ACKNOWLEDGMENT}

V. Youssofzadeh was supported by the University of Ulster Vice-Chancellors Research Scholarship award. D. Zanotto and S.K. Agrawal were supported in part by grants NSF IIS1339666 and NYS SCIRB Award C030168. K. Wong-Lin and G. Prasad were supported in part by the Northern Ireland Functional Brain Mapping Facility (1303/101154803), funded by InvestNI and University of Ulster. G. Prasad was also supported in part by the UKIERI DST Thematic Partnership project: A BCI operated hand exoskeleton based neurorehabilitation system (UKIERI-DST-2013-141126).

\section{REFERENCES}

[1] J.-M. Belda-Lois, S. Mena-del Horno, I. Bermejo-Bosch, J. C. Moreno, J. L. Pons, D. Farina, M. Iosa, M. Molinari, F. Tamburella, A. Ramos, A. Caria, T. Solis-Escalante, C. Brunner, and M. Rea, "Rehabilitation of gait after stroke: a review towards a top-down approach," Journal of NeuroEngineering and Rehabilitation, vol. 8, no. December, p. 66, 2011.

[2] S. Makeig, K. Gramann, T.-P. Jung, T. J. Sejnowski, and H. Poizner, "Linking brain, mind and behavior." International Journal of Psychophysiology, vol. 73, no. 2, pp. 95-100, 2009.

[3] K. Gramann, J. T. Gwin, N. Bigdely-Shamlo, D. P. Ferris, and S. Makeig, "Visual evoked responses during standing and walking." Frontiers in human neuroscience, vol. 4, no. October, p. 202, jan 2010.

[4] T. M. Lau, J. T. Gwin, and D. P. Ferris, "Walking reduces sensorimotor network connectivity compared to standing." Journal of neuroengineering and rehabilitation, vol. 11, no. 1, p. 14, feb 2014.

[5] J. T. Gwin, K. Gramann, S. Makeig, and D. P. Ferris, "Electrocortical activity is coupled to gait cycle phase during treadmill walking." NeuroImage, vol. 54, no. 2, pp. 1289-96, jan 2011.

[6] J. Wagner, T. Solis-Escalante, P. Grieshofer, C. Neuper, G. MüllerPutz, and R. Scherer, "Level of participation in robotic-assisted treadmill walking modulates midline sensorimotor EEG rhythms in able-bodied subjects," NeuroImage, vol. 63, no. 3, pp. 1203-1211, 2012.
[7] a. Presacco, R. Goodman, L. Forrester, and J. L. Contreras-Vidal, "Neural decoding of treadmill walking from noninvasive electroencephalographic signals," Journal of Neurophysiology, vol. 106, no. 4, pp. 1875-1887, 2011.

[8] M. Seeber, R. Scherer, J. Wagner, T. Solis-Escalante, and G. R. MüllerPutz, "High and low gamma EEG oscillations in central sensorimotor areas are conversely modulated during the human gait cycle," NeuroImage, vol. 112, pp. 318-326, 2015.

[9] M. Seeber, R. Scherer, J. Wagner, T. Solis-Escalante, and G. R. MullerPutz, "EEG beta suppression and low gamma modulation are different elements of human upright walking," Frontiers in Human Neuroscience, vol. 8, no. July, pp. 1-9, 2014.

[10] J. Raethjen, R. B. Govindan, S. Binder, K. E. Zeuner, G. Deuschl, and H. Stolze, "Cortical representation of rhythmic foot movements." Brain research, vol. 1236, pp. 79-84, oct 2008.

[11] C. S. Inman, G. A. James, S. Hamann, J. K. Rajendra, G. Pagnoni, and A. J. Butler, "Altered resting-state effective connectivity of frontoparietal motor control systems on the primary motor network following stroke," NeuroImage, vol. 59, pp. 227-237, 2012.

[12] T. C. Bulea, J. Kim, D. L. Damiano, C. J. Stanley, and H.-S. Park, "Prefrontal, posterior parietal and sensorimotor network activity underlying speed control during walking," Frontiers in Human Neuroscience, vol. 9, no. May, 2015.

[13] M. Wieser, J. Haefeli, L. Bütler, L. Jäncke, R. Riener, and S. Koeneke, "Temporal and spatial patterns of cortical activation during assisted lower limb movement," Experimental Brain Research, vol. 203, no. 1, pp. 181-191, 2010.

[14] A. R. Sipp, J. T. Gwin, S. Makeig, and D. P. Ferris, "Loss of balance during balance beam walking elicits a multifocal theta band electrocortical response." Journal of neurophysiology, vol. 110, no. 2009, pp. 2050-60, 2013

[15] T. H. Petersen, M. Willerslev-Olsen, B. a. Conway, and J. B. Nielsen, "The motor cortex drives the muscles during walking in human subjects." The Journal of physiology, vol. 590, pp. 2443-52, 2012.

[16] J. Ushiyama, Y. Masakado, T. Fujiwara, T. Tsuji, K. Hase, A. Kimura, M. Liu, and J. Ushiba, "Contraction level-related modulation of corticomuscular coherence differs between the tibialis anterior and soleus muscles in humans," Journal of Applied Physiology, vol. 112, pp. 12581267, 2012.

[17] M. Ding, Y. Chen, and S. S. L. Bressler, "Granger Causality: Basic Theory and Application to Neuroscience," in Handbook of time series analysis, B. Schelter, M. Winterhalder, and J. Timmer, Eds. Weinheim, Germany: Wiley-VCH Verlag GmbH \& Co. KGaA, sep 2006, no. February, ch. 17, pp. 437-460.

[18] V. Youssofzadeh, D. Zanotto, P. Stegall, M. Naeem, K. Wong-Lin, S. K. Agrawal, and G. Prasad, "Directed neural connectivity changes in robotassisted gait training: A partial Granger causality analysis," in IEEE Engineering in Medicine \& Biology Society. Chicago: IEEE, 2014, pp. 6361-6364.

[19] S. Guo, A. K. Seth, K. M. Kendrick, C. Zhou, and J. Feng, "Partial Granger causality-eliminating exogenous inputs and latent variables." Journal of neuroscience methods, vol. 172, no. 1, pp. 79-93, jul 2008.

[20] V. Youssofzadeh, G. Prasad, M. Naeem, and K. Wong-Lin, "Temporal information of directed causal connectivity in event related potentials using partial Granger causality," Neuroinformatics, no. 2000, pp. 1-22, 2015.

[21] P. Stegall, K. Winfree, D. Zanotto, and S. Agrawal, "Rehabilitation Exoskeleton Design: Exploring the Effect of the Anterior Lunge Degree of Freedom," vol. 29, no. 4, pp. 838-846, 2013.

[22] D. Zanotto, Y. Akiyama, P. Stegall, and S. K. Agrawal, "Knee Joint Misalignment in Exoskeletons for the Lower Extremities: Effects on User's Gait," IEEE Transactions on Robotics, vol. 31, no. 4, pp. 978987, 2015.

[23] R. Schmidt, "Frequent Augmented Feedback Can Degrade Learning: Evidence and Interpretations," Tutorials in Motor Neuroscience SE - 6 , vol. 62 , pp. $59-75,1991$.

[24] Magill, Richard A. and D. Anderson, Motor learning and control: Concepts and applications, 11th ed. New York: McGraw-Hill, 2007.

[25] D. Zanotto, G. Rosati, S. Spagnol, P. Stegall, and S. Agrawal, "Effects of complementary auditory feedback in robot-assisted lower extremity motor adaptation," IEEE Transactions on Neural Systems and Rehabilitation Engineering, vol. 21, no. 5, pp. 775-86, sep 2013.

[26] a. J. Bell and T. J. Sejnowski, "An information-maximization approach to blind separation and blind deconvolution." Neural computation, vol. 7 , no. 6, pp. 1129-59, nov 1995.

[27] A. Presacco, L. Forrester, and J. L. Contreras-Vidal, "Decoding intralimb and inter-limb kinematics during treadmill walking from scalp 
electroencephalographic (EEG) signals," IEEE Transactions on Neural Systems and Rehabilitation Engineering, vol. 20, no. 2, pp. 212-219, 2012.

[28] M. Ding, S. L. Bressler, W. Yang, and H. Liang, "Short-window spectral analysis of cortical event-related potentials by adaptive multivariate autoregressive modeling: data preprocessing, model validation, and variability assessment." Biological cybernetics, vol. 83, no. 1, pp. 35-45, jul 2000

[29] M. Morf, A. Vieira, D. T. L. Lee, and T. Kailath, "Recursive Multichannel Maximum Entropy Spectral Estimation," IEEE Transactions on Geoscience Electronics, vol. 16, pp. 85-94, 1978.

[30] J. Durbin and G. S. Watson, "Testing for serial correlation in least squares regression. II." Biometrika, vol. 38, pp. 159-178, 1951

[31] B. Efron and R. J. Tibshirani, An Introduction to the Bootstrap. CRC Press, 1994, vol. 57.

[32] I. H. Harding, M. Yücel, B. J. Harrison, C. Pantelis, and M. Breakspear, "Effective connectivity within the frontoparietal control network differentiates cognitive control and working memory," NeuroImage, vol. 106, pp. 144-153, 2015.

[33] K.-F. Wong and A. C. Huk, "Temporal Dynamics Underlying Perceptual Decision Making: Insights from the Interplay between an Attractor Model and Parietal Neurophysiology." Frontiers in neuroscience, vol. 2, no. 2, pp. 245-54, dec 2008.

[34] J.-P. Liu, C. Zhang, and C.-X. Zheng, "Estimation of the cortical functional connectivity by directed transfer function during mental fatigue." Applied ergonomics, vol. 42, no. 1, pp. 114-21, dec 2010.

[35] V. Siemionow, V. Sahgal, and G. H. Yue, "Single-Trial EEG-EMG coherence analysis reveals muscle fatigue-related progressive alterations in corticomuscular coupling." IEEE transactions on neural systems and rehabilitation engineering, vol. 18, no. 2, pp. 97-106, apr 2010.

[36] Q. Yang, Y. Fang, C.-K. Sun, V. Siemionow, V. K. Ranganathan, D. Khoshknabi, M. P. Davis, D. Walsh, V. Sahgal, and G. H. Yue, "Weakening of functional corticomuscular coupling during muscle fatigue," Brain Research, vol. 1250, pp. 101-112, 2009.

[37] J. van Driel, K. R. Ridderinkhof, and M. X. Cohen, "Not All Errors Are Alike: Theta and Alpha EEG Dynamics Relate to Differences in Error-Processing Dynamics," Journal of Neuroscience, vol. 32, no. 47, pp. 16795-16806, 2012.

[38] M. Wieser, J. Haefeli, L. Bütler, L. Jäncke, R. Riener, and S. Koeneke, "Temporal and spatial patterns of cortical activation during assisted lower limb movement." Experimental brain research, vol. 203, no. 1, pp. 181-91, may 2010.

[39] D. Zanotto, T. Lenzi, P. Stegall, and S. K. Agrawal, "Improving transparency of powered exoskeletons using force/torque sensors on the supporting cuffs," IEEE International Conference on Rehabilitation Robotics, pp. 0-5, 2013.

[40] S. L. Bressler, W. Tang, C. M. Sylvester, G. L. Shulman, and M. Corbetta, "Top-down control of human visual cortex by frontal and parietal cortex in anticipatory visual spatial attention." The Journal of neuroscience : the official journal of the Society for Neuroscience, vol. 28, no. 40, pp. $10056-61$, oct 2008.

[41] G. Bush, P. Luu, and M. Posner, "Cognitive and emotional influences in anterior cingulate cortex." Trends in cognitive sciences, vol. 4, no. 6 , pp. 215-222, jun 2000.

[42] L. Wang, X. Liu, K. G. Guise, R. T. Knight, J. Ghajar, and J. Fan, "Effective connectivity of the fronto-parietal network during attentional control." Journal of cognitive neuroscience, vol. 22, pp. 543-553, 2010.

[43] J. E. Kline, K. Poggensee, and D. P. Ferris, "Your brain on speed: cognitive performance of a spatial working memory task is not affected by walking speed." Frontiers in human neuroscience, vol. 8, no. May, p. 288, jan 2014.

[44] S. Haufe, V. V. Nikulin, K.-R. Müller, and G. Nolte, "A critical assessment of connectivity measures for EEG data: a simulation study." NeuroImage, vol. 64, pp. 120-33, jan 2013.

[45] G. Gómez-Herrero, M. Atienza, K. Egiazarian, and J. L. Cantero, "Measuring directional coupling between EEG sources." NeuroImage, vol. 43, no. 3, pp. 497-508, nov 2008.

[46] R. Srinivasan, W. R. Winter, J. Ding, and P. L. Nunez, "EEG and MEG coherence: Measures of functional connectivity at distinct spatial scales of neocortical dynamics," Journal of Neuroscience Methods, vol. 166, no. 1, pp. 41-52, 2007.

[47] W. R. Winter, P. L. Nunez, J. Ding, and R. Srinivasan, "Comparison of the effect of volume conduction on EEG coherence with the effect of field spread on MEG coherence," Statistics in Medicine, vol. 26, no. 21, pp. 3946-3957, 2007.

[48] M. Vinck, L. Huurdeman, C. a. Bosman, P. Fries, F. P. Battaglia, C. M. Pennartz, and P. H. Tiesinga, "How to detect the Granger-causal flow direction in the presence of additive noise?" NeuroImage, vol. 108, pp. 301-318, 2015.

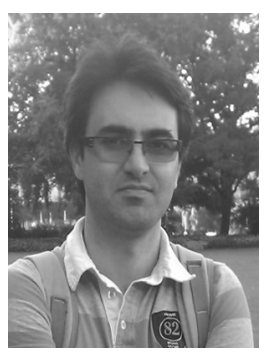

Vahab Youssofzadeh received his Ph.D. degree in computer science from Ulster University, UK, in 2016. During his Ph.D., he worked on computational analysis and modelling of dynamic brain connectivity. Since Dec 2015, he has been a research associate at Intelligent Systems Research Centre, Ulster University. His research interests include effective connectivity analysis of brain responses using $\mathrm{M} / \mathrm{EEG}$ data and machine learning analysis of cohort imaging (MRI and PET) data to classify Alzheimer's disease.

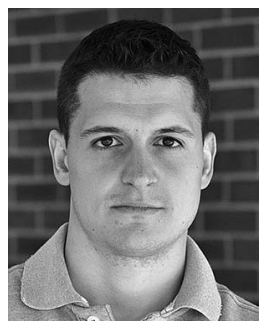

Damiano Zanotto (M'12) received Bachelor's and Master's degrees in Mechanical Engineering in 2005 and 2007, respectively, as well as a Ph.D. degree in Industrial Engineering (curriculum in Mechatronics) in 2011, all from the University of Padua, in Padua, Italy. Between 2011 and 2013, he was a Postdoctoral Researcher with the Mechanical Systems Laboratory (MSL), University of Delaware, Newark, DE, US. Since 2013 he has been working with the Robotics and Rehabilitation (ROAR) Laboratory at Columbia University (New York, NY, US) as an Associate Research Scientist. His research interests include assistive and rehabilitation robotics, wearable technology, and cable-driven robotic devices.

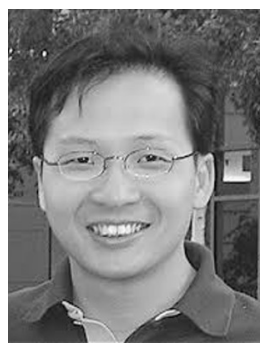

KongFatt Wong-Lin is a Lecturer (equivalent to Assistant Professor) in Computational Neuroscience at the Intelligent Systems Research Centre, Ulster University, UK. He received his Ph.D. in Physics (Computational Neuroscience) at Brandeis University, USA, followed by a Research Associate position at Princeton University, USA, affiliated with The Program in Applied and Computational Mathematics, the Center for the Study of Brain, Mind and Behavior, and Princeton Neuroscience Institute.

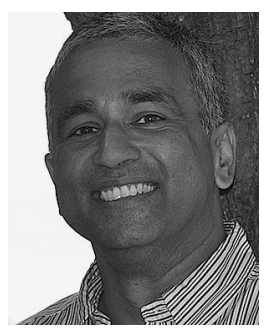

Sunil Agrawal (M'92) received the Ph.D. degree in mechanical engineering from Stanford University, Stanford, CA, USA, in 1990. He is currently a Professor with the Department of Mechanical Engineering, Columbia University, New York, NY, USA. He has authored more than 400 journal and conference papers and two books in the areas of controlled mechanical systems, dynamic optimization, and robotics. He has been an editorial board member of ASME and the IEEE journals. Dr. Agrawal is a Fellow of the American Society of Mechanical Engineers (ASME) and American Institute for Medical and Biological Engineering (AIMBE). He received a Presidential Faculty Fellowship from the White House, a Bessel Prize in Germany, and a Humboldt U.S. Senior Scientist Award.

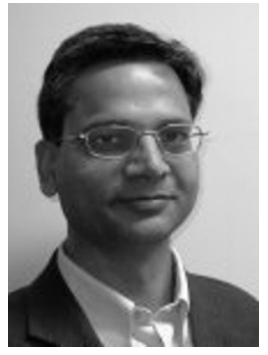

Girijesh Prasad (M'98-SM'07) received the BTech degree in Electrical Engineering in 1987, the MTech degree in Computer Science and Technology in 1992, and the PhD degree from Queens University, Belfast, UK in 1997. He currently holds the post of Professor of Intelligent Systems in the School of Computing and Intelligent Systems, Ulster University, Magee campus. As an executive member of Intelligent Systems Research Centre at Magee campus, he leads the Neural Systems and Neurotechnology team. He is the Director of Northern Ireland Functional Brain Mapping facility for MEG studies. His research interests are in computational intelligence, brain modelling, brain-computer interfaces and neuro-rehabilitation, and assistive robotic systems. He has published over 200 research papers in international journals, books, and conference proceedings. Prof. Prasad is a Chartered Engineer and a fellow of the IET. He is a founder member of IEEE SMC TCs on Brain-Machine Interface Systems and Evolving Intelligent Systems. 